\title{
«DEL BUEN HUMOR AJENO»: EL LUGAR DE LA TRADUCCIÓN EN LAS NUEVAS FORMAS DE LA LITERATURA HUMORÍSTICA
}

\author{
«FROM ALIEN GOOD HUMOR»: THE PLACE OF \\ TRANSLATION IN THE NEW FORMS OF HUMOR \\ LITERATURE
}

\author{
Juan Carlos Pueo \\ Instituto de Patrimonio y Humanidades \\ Universidad de Zaragoza
}

\section{ABSTRACT}

The translation of humor literature not only faces problems similar to those posed by the theory of translation in different literary modalities, but also must face its own problems, derived from issues related to the cultural field of humor, especially the linguistic peculiarities of comic literature in its historical moment. This paper describes a specific case, that of the section «Of alien good humor» in the early years of Buen Humor magazine (1921-22), when a new way of laughter was opposed to the festive comedy of the previous decades through the resource of absurd humor, linked to the emergence of the literary avant-garde and the need of a new generation of humorists of asserting themselves.

Key words: Humor, translation, avant-garde, Buen Humor, José López Rubio 


\section{RESUMEN}

La traducción de la literatura humorística no sólo se enfrenta a problemas semejantes a los que plantea la teoría de la traducción en diferentes modalidades literarias, sino que debe afrontar una problemática propia, derivada de cuestiones relacionadas con el campo cultural del humor, en especial las peculiaridades lingüísticas de la literatura cómica en su momento histórico. En este artículo se describe un caso concreto, el de la sección «Del buen humor ajeno en los primeros años de la revista Buen Humor (1921-22), cuando a la comicidad festiva de las décadas previas se le opuso una nueva forma de hacer reír mediante el recurso del humor absurdo, vinculado a la eclosión de las vanguardias literarias y a la necesidad de afirmarse de una nueva generación de humoristas.

Palabras clave: humor, traducción, vanguardia, Buen Humor, José López Rubio.

Fecha de recepción: 31 de agosto de 2021.

Fecha de aceptación: 22 de septiembre de 2021.

Cómo citar: Pueo, Juan Carlos (2021): “"Del buen humor ajeno”: el lugar de la traducción en las nuevas formas de la literature humorística», en Actio Nova: Revista de Teoría de la Literatura y Literatura Comparada, monográfico 5:141-156.

DOI: https://doi.org/10.15366/actionova2021.m5.007 
El campo cultural del humor se caracteriza no sólo por la inagotable variedad de formatos en los que éste se manifiesta, sino por las estrechas relaciones que se establecen entre todos ellos. La risa suele apuntar casi siempre en la misma dirección, lo que hace que a menudo se produzcan todo tipo de convergencias entre los medios de excitarla. Esto no impide, por otra parte, que se produzcan en su devenir cambios significativos, al calor siempre de las dinámicas culturales que se integran en el superconjunto de la historia de las mentalidades. Una historia global de la risa sólo podrá llevarse a cabo atendiendo a su carácter cultural, es decir, a las implicaciones que se establecen con otros campos no menos complejos, sobre todo dentro de los dominios de la literatura y las artes.

No cabe duda de que los años veinte del pasado siglo fueron uno de esos momentos clave en que el modelo humorístico vigente en las décadas anteriores fue dejando paso a otra forma completamente distinta de entender la risa, con la que ya no podría dejar de convivir —no se crea, sin embargo, que el modelo previo desapareció de la noche a la mañana; por el contrario, se ha mantenido vigente durante estos últimos cien años, aunque cada vez con menos fuerza-. No es menos cierto, por otra parte, que el cambio de modelo se produjo en un momento de efervescencia cultural particularmente intenso, el de la eclosión de la literatura y el arte vanguardistas, si bien hay que matizar que las relaciones entre los movimientos de vanguardia y la práctica del humorismo no siempre se perciben a primera vista, y tienen más que ver con el espíritu común de la generación que había nacido con el cambio de siglo que con una verdadera convergencia de proyectos estéticos: no es tanto que el humor siguiese la estela de la vanguardia, sino que, más bien, era la vanguardia la que se sentía atraída hacia el humor ${ }^{1}$, sobre todo el que se salía de las viejas formas. Pero ya volveremos a ello.

El humor ocupa todos los medios posibles para hacerse ver, oír y leer por parte de un público mayoritario que lo busca y lo aprecia en casi todos los ámbitos de la vida cotidiana. En aquella época, como en la actual, el humor se puede encontrar en el teatro, en los espectáculos de circo y variedades, en el libro, en la prensa — no sólo en forma de artículos, también en el humor gráfico-, en el cine y en la radio, además de la cultura popular de

\footnotetext{
1 «El poeta reirá como un motor de avión»: Guillermo de Torre citaba en Literaturas europeas de vanguardia (1925: 162) esta afirmación del poeta dadá Paul Neuhuys para evidenciar la afinidad de los vanguardismos con una nueva forma de reír que tomaba forma de manera evidente en todos los ámbitos culturales del momento. También Ortega y Gasset lo vio claramente en La deshumanización del arte: «no puede menos de extrañar a quien para en ello mientes que la nueva inspiración es siempre, indefectiblemente, cómica. Toda ella suena en esa sola cuerda y tono. La comicidad será más o menos violenta y correrá desde la franca clownería hasta el leve guiño irónico, pero no falta nunca» (Ortega y Gasset, 1925: 79).
} 
transmisión oral, en forma de chistes y canciones burlescas. No es extraño que en esta variedad se produzcan todo tipo de tensiones que darán pie a la aparición de las nuevas formas humorísticas, asimiladas rápidamente por un público que en principio podía mostrarse reacio a estas novedades, pero que al final acababa aceptándolas por su efectividad a la hora de despertar sus carcajadas.

A comienzos del siglo $\mathrm{Xx}$, la risa tenía su espacio privilegiado en los escenarios teatrales, donde las formas de teatro cómico convivían con los géneros «serios», en especial con el melodrama y la alta comedia. Se trataba de una risa sencilla e ingenua, centrada muchas veces en conflictos y personajes estereotipados a los que se añadían numerosos juegos de palabras sin mayor sustancia, y al que se daba el nombre de «humor festivo». Nada que ver con el teatro minoritario de Valle-Inclán o Azorín, representantes más o menos imprevistos de un humorismo teatral completamente diferente del que se estilaba en aquellos años, y al que no voy a tener oportunidad de referirme en el contexto de este artículo. El teatro cómico que triunfaba en aquellos años era el de los sainetes de Arniches y las astracanadas de Muñoz Seca y García Álvarez ${ }^{2}$, un teatro que se situaba dentro de lo que Pierre Bourdieu (1992) llama «la gran producción», esto es, obras que gozaban del favor del público, generando grandes beneficios económicos, y que se justificaban con el simple propósito de hacer reír sin mayores pretensiones a una clientela que sólo buscaba un teatro de evasión.

Este humor festivo tenía menor presencia en la prensa ${ }^{3}$, donde se cultivaban o bien la sátira política más o menos vitriólica, en cabeceras como Madrid Cómico, Gedeón o El Duende, o bien la estampa erótica —a veces directamente pornográfica一, en jAbi va!, La Hoja de Parra o Mundo Galante. El teatro era todavía entonces un espectáculo de masas, por lo que cualquier exceso en el terreno político era rápidamente reprimido, mientras que lo sicalíptico quedaba confinado al ámbito del «género ínfimo» y la revista. La prensa, en cambio, tenía mayor libertad para tratar este tipo de contenidos, que si bien alcanzaron gran popularidad en las dos primeras décadas del siglo, dieron ya en los años veinte algunas muestras de cansancio, hasta que el establecimiento de la censura previa con la dictadura de Primo de Rivera hizo que estas dos temáticas fuesen inviables.

\footnotetext{
2 Sin duda se trataba del teatro más popular de la época, pero habría que añadirle otras manifestaciones escénicas como los monólogos humorísticos que llevaban a cabo figuras igualmente famosas como Ramper o Luis Esteso en el ámbito de los espectáculos de circo y variedades, que todavía están por estudiar.

${ }^{3}$ Para una revisión de las revistas humorísticas de la época, véase Rodríguez de la Flor (1990; 1993) y López Ruiz (1995; 2006).
} 
Antes de 1923, con todo, había salido una revista titulada Buen Humor en la que lo político y lo erótico habían empezado a tener un lugar muy secundario para centrarse en ese humor festivo característico de la escena teatral más popular. El primer número de la revista, que había aparecido el 4 de diciembre de 1921, incorporaba las firmas de, entre otros, Wenceslao Fernández Flórez, Luis de Tapia, Manuel Abril, Ramón Gómez de la Serna y José López Rubio. A ellos se unirían posteriormente los nombres, igualmente famosos en aquellos años, de Juan Pérez Zúñiga, Ernesto Polo, Carlos Luis de Cuenca y Agustín Rodríguez Bonnat, todos ellos caracterizados por ese humor blanco que se convertiría en seña de identidad de la revista, pues, como recordaba cuatro décadas despues Miguel Mihura, Buen Humor

[...] podía llegar a todas las manos y estar encima de la mesa camilla de todos los hogares junto al $A B C$ y al Blanco y Negro y La Moda en España. Porque aquella revista $[\ldots]$ fue la primera que no teníamos necesidad de leer a escondidas los que teníamos dieciséis años, y la que empezaron a leer también nuestras hermanas, sorprendidas de que existiera para ellas una literatura que no las obligara a llorar a cántaros por la muerte del hijo ilegítimo de una vizcondesa en un día de nieve (Mihura, 1966: 1299).

Dirigida por el caricaturista Pedro Antonio Villahermosa, «Sileno», Buen Humor pretendía ser, desde el primer número, una publicación de referencia en la que tuvieran cabida otras formas de humorismo que, sin salirse de la línea editorial comentada, pudieran dar cuenta del panorama en que aquel se encontraba en aquellos momentos. Junto con los artículos, cuentos y viñetas destinados a provocar la risa del lector, había también una sección dedicada a la estética del humor desde un punto de vista algo más serio, en la que José Francés analizaba la obra de los mejores humoristas gráficos del momento. Y desde el primer número se incluyó una sección titulada «Del buen humor ajeno» en la que se incluían traducciones de textos extranjeros, predominantemente franceses, con la intención de dar a conocer las producciones de quienes escribían más allá de nuestras fronteras ${ }^{4}$. A partir del número 3 de la revista, esta sección se complementaría con viñetas procedentes de periódicos y revistas como Punch, Life, Le Rire, Pasquino o Lustigz Blätter, entre otras muchas.

\footnotetext{
${ }^{4}$ Se trata de textos breves publicados, presumiblemente, en revistas francesas de la época. La mayoría de los autores traducidos son franceses, y es muy probable que los textos de humoristas procedentes de otros países, pero de fama mundial -Mark Twain, Anton Chéjov-, tuvieran el mismo origen. Los nombres más habituales son los de Max y Alex Fischer, Tristan Bernard, Pierre Veber, Alphonse Allais o Cami. Dado el olvido en que han caído estos autores después de cien años, la tarea de encontrar los textos originales de los que surgieron las traducciones de Buen Humor ha sido imposible de llevar a cabo con éxito.
} 
La publicación de textos traducidos formaba parte, pues, de la política editorial de la revista, atenta no sólo a provocar la risa del lector sino también a ofrecerle una mirada informada sobre el humorismo, incluyendo las opciones más adelantadas: los populares e inocentes versos de Tapia y Pérez Zúñiga convivían con los artículos de Ramón Gómez de la Serna, que ofrecían una mirada innovadora en torno a diferentes cuestiones de la vida cotidiana, o las colaboraciones de un jovencísimo - dieciocho años- José López Rubio, que era además secretario de redacción de la revista, cuyas puertas abriría en poco tiempo a otros artistas igualmente jóvenes, deseosos de romper con las viejas formas del humorismo: Enrique Jardiel Poncela, Edgar Neville, Antonio Robles, Miguel Mihura, Tono, etc.

José López Rubio se encargaría, precisamente, de las traducciones que aparecen en la sección «Del buen humor ajeno» de los números 2, 3 y 7 de Buen Humor. Posteriormente, las traducciones quedarían encargadas a otros autores, difíciles de identificar porque solamente se dan a conocer sus iniciales: si «J. L. R.» se deja reconocer fácilmente, no ocurre lo mismo con «A. R.»-¿Antonio Robles?_, «A. G.» o «M. V.». Las traducciones hechas por López Rubio, así como algunas de las que ofrecen sus compañeros de redacción, tienen un particular atractivo por lo que revelan acerca de los intereses de la revista. En primer lugar, porque no cabe duda de que los textos traducidos cumplen la función de espolear la imaginación de las generaciones más jóvenes, revelándoles nuevas formas de creatividad a las que pueden dirigir su deseo de renovación, tal como indica Itamar Even-Zohar:

Decir que la literatura traducida ocupa una posición central en el polisistema literario significa que participa activamente en la configuración del centro del polisistema. En tal caso forma parte integrante de las fuerzas innovadoras y como tal es posible considerarla entre los acontecimientos más importantes en la historia literaria mientras éstos tienen lugar. Ello quiere decir que, en esta situación, no se puede mantener una distinción nítida entre textos «originales» y textos «traducidos», y que muchas veces son destacados escritores (o los miembros de la vanguardia a punto de convertirse en tales) los que realizan las traducciones más notables y apreciadas. Más aún, en tal estado de cosas, en el momento en que emergen nuevos modelos literarios, la traducción suele convertirse en uno de los instrumentos de elaboración del nuevo repertorio. A través de obras extranjeras se introducen en la literatura local ciertos rasgos (tanto principios como elementos) antes inexistentes. Así se incluyen posiblemente no sólo nuevos modelos de realidad que sustituyan a los antiguos y a otros bien asentados ya no operativos, sino también toda otra serie de rasgos, como un lenguaje (poético) nuevo o nuevos modelos y técnicas compositivas. Es evidente que los propios criterios de selección de las obras que son traducidas vienen determinados por la situación reinante en el polisistema local: los textos son elegidos según su compatibilidad con las nuevas tendencias y con el papel supuestamente innovador que pueden asumir dentro de la literatura receptora (Even-Zohar, 1990: 225). 
El cuento humorístico, tal como lo practicaban a comienzos de los años veinte los redactores de Buen Humor, sigue las principales líneas del humor festivo preponderante en la escena teatral. Los contenidos suelen centrarse en la figura del «fresco», personaje arquetípico de la comedia astracanesca que busca por todos los medios vivir de los demás, casi siempre con alguna estratagema engañosa —no siempre sutil— que le permitirá salir triunfante en algunas ocasiones, si bien lo más habitual es que fracase estrepitosamente. En cualquier caso, la fuente del humor es siempre el chasco que se lleva algún personaje, ya se trate del «fresco» o de sus víctimas. En lo formal, la risa se busca a menudo por medio de juegos de palabras basados en la dilogía o doble sentido, muchas veces de muy baja calidad, aunque hay que señalar que en esta época eran muy apreciados por el público. Así, por ejemplo, en «La cena del poeta», de Ernesto Polo:

Pero dejemos al amor hablar de lo que quiera; ciñámonos a nuestra historia, y fijemos la mirada en un punto...

Este punto es un poeta, de Burgos y fresco (¿queso?), que hace media hora anda dando vueltas por la Puerta del Sol, sumido en una duda horrible. ¿Debe entrar a cenar en el café Colonial o no debe?... Tratándose de un poeta, yo afirmo que debe, afirmación que el vate corrobora decidiéndose por fin a entrar en el café susodicho, que, como sabemos todos los madrileños, está abierto toda la noche (precios de la militar).

El gentil trovador, a quien llamaremos Domingo de Ramos, hace palmas, y un gallardo mozo se acerca...

一 ¡La lista grande!...

Domingo la lee, y, aunque es lo corriente que en la lista grande busquemos el gordo, el poeta busca el solomillo...

Pero al pedir, pide no sólo millo. sino también frito variado, merluza con tártara y pepitoria de gallina... (Polo, 1921: 18-19; cursiva en el texto).

La anécdota del cuento es trivial, pues se limita a mostrar a su protagonista consumiendo una cena opípara para declarar después que quiere terminar con dos guindillas... que le llevarán a comisaría, dado que no puede pagarla. Con todo, ya se ha señalado que la fórmula gozaba de gran éxito en aquellos años, por lo que no es de extrañar que los humoristas consagrados se ciñeran habitualmente a ella, e incluso los noveles comenzasen imitando este tipo de contenidos. La primera colaboración de Enrique Jardiel Poncela en Buen Humor es un cuento titulado «Un negocio productivo» en el que narra la historia de un joven que roba un collar de diamantes para descubrir posteriormente que el collar es falso, mientras que en la aventura ha perdido su anillo, que tenía engastado un diamante verdadero. El cuento va sazonado con los pertinentes juegos de palabras al uso: 
Berriachea, que era castaño, no se andaba por las ramas. Cogió los valiosos enseres de su casa, y, metiendo los enseres en seras y en serones, los fue trasladando a esos locales, todo cordialidad y poesía, que se llaman casas de préstamos. Cuanto llevaba Heliodoro les interesaba mucho a aquellos señores, y digo esto porque se lo tomaban con un gran interés (Jardiel Poncela, 1922: 1).

Esta predilección por los juegos de palabras de carácter dilógico establece una diferencia esencial respecto a los textos publicados en la sección «Del buen humor ajeno». Evidentemente, los textos seleccionados no podían ser del mismo tipo que los que se publicaban en la revista, pues los juegos de palabras —especialmente las dilogías - tienen el inconveniente de no ser siempre traducibles a otro idioma, so pena de perder toda su gracia. La selección de textos traducibles había de hacerse, pues, siguiendo otros criterios. Cierto que quedaba todavía la posibilidad de acudir a la figura del «fresco»—en efecto, son abundantes los cuentos en los que se narra alguna forma de engaño, con o sin éxito para quien lo perpetra-, pero la búsqueda de textos que se ajustasen a la línea editorial de la revista logró que se aceptasen algunos completamente novedosos que hasta ese momento no habrían tenido cabida en la prensa humorística española.

La presencia en las traducciones de textos extranjeros de elementos extraños a la sensibilidad del lector, ajenos a su horizonte de expectativas, implica para el traductor la necesidad de elegir entre dos opciones, tal como señala Gaston Toury:

Se ha demostrado que resulta útil e instructivo examinar la elección básica que se puede hacer entre los requisitos de las dos fuentes como si constituyese una norma inicial. Así, un traductor puede someterse o bien al texto original, con las normas que éste ha materializado, o bien a las normas activas en la cultura receptora o en aquella parte de ella en la que podría insertarse el producto final. Si se adopta la primera postura, la traducción tenderá a suscribir las normas del texto fuente $\mathrm{y}$, a través de ellas, también las normas del lenguaje y de la cultura fuente. Esta tendencia, que muchas veces ha sido considerada como una búsqueda de una traducción adecuada, puede conllevar incompatibilidades con las normas y las prácticas de recepción, especialmente aquellas que se esconden tras las puramente lingüísticas. Si, por otro lado, se adopta la segunda postura, se ponen en funcionamiento los sistemas normativos de la cultura receptora. Las transformaciones del texto original serían el precio casi inevitable que habría que pagar. Así, mientras la adhesión a las normas fuente determina la adecuación de la traducción en relación al texto fuente, el hecho de suscribir las normas de la cultura receptora determina su aceptabilidad (Toury, 1995: 237-238; cursiva en el texto).

En el caso de las traducciones de textos humorísticos, hay que contar con la capacidad del receptor para percibir, como señala Arthur Koestler, «una situación o idea en dos marcos de referencia bien consistentes pero habitualmente incompatibles» (1964: 199). 
El lector de los relatos publicados en Buen Humor, habituado a los infantiles juegos de palabras del humor festivo, se encontraba, pues, con unos textos en los que se le incitaba a reír por otros medios, lo que no podía sino generar una duda bastante razonable acerca de la consistencia de los campos de referencia cuyo contraste debía suscitar la risa. En otras palabras, y siguiendo la disyuntiva planteada por Toury, ¿`sería el lector de aquel momento lo suficientemente perspicaz para percibir por sí solo este contraste, o se le debería guiar de alguna forma para hacerle más fácil dicha percepción?

El primero de los textos traducidos por José López Rubio opta por la segunda vía, tratando de hacer el texto traducido «aceptable» para los lectores. El cuento, titulado «Un artista», remite no tanto al texto original como a la concepción que lo ha inspirado, ya que se informa al lector de que el texto se trata de una «idea de Max y Alex Fischer» ${ }^{5}$, lo que indica que la labor de López Rubio no se ha limitado a la traslación de un idioma a otro, sino que ha procurado adaptar el texto de alguna manera. El mismo procedimiento se había adoptado en el número anterior, donde se había publicado un cuento titulado «La lucha por la vida» según una «idea de Marcel Sedano», adaptación atribuida en esta ocasión a «E. U.» -probablemente Eduardo Ugarte-.

La «idea» de la que surge el humor en «Un artista» es un planteamiento equívoco que nada tiene que ver esta vez con los afanes del «fresco» para timar a sus víctimas: el relato cuenta la historia de Matías, al que se presenta como un joven que «se sentía atraído invenciblemente por el arte pictórico» (Fischer, 1921: 14). La narración adopta entonces la falsilla de la biografía de un pintor que comienza aprendiendo los rudimentos de su arte en el taller de un maestro, hasta que empieza a abrirse paso mediante la realización de varias obras, culminando su carrera con su participación en el Salón de Otoño y un encargo para nada menos que el Museo del Prado. El equívoco consistía en que las obras que pinta Matías no pertenecen al ámbito del arte, sino que se trata de rótulos publicitarios o letreros indicadores. El narrador los trata, sin embargo, como si fueran obras de arte al mismo nivel que las más acreditadas:

Su primera obra seria tuvo la desgraciada suerte del Ángelus, de Millet. Fue vendida por un precio vil a un anticuario; era un gran lienzo blanco y en colores

\footnotetext{
${ }^{5}$ Max (1880-1957) y Alex Fischer (1881-1935) estrenaron con éxito algunas comedias teatrales, si bien los textos que más fama les dieron fueron sus novelas y sus cuentos, publicados en diversas cabeceras como Petit Journal o L'Écho de Paris. Ejercieron también la labor de directores editoriales para Flammarion, donde publicaron buena parte de sus obras.
} 
muy sobrios —no había utilizado más que tierra de Siena-, y en él se leía: «Liquidación general por fin de temporada».

Sin desanimarse, tomó de nuevo sus pinceles con afán y produjo entonces un Restaurant a precio fijo. Hay billares, que se expuso en la calle de la Visitación, esquina a Echegaray. Dio la última pincelada a una Probibida la entrada al público (1914), a una Obras depavimentación, a un Llamad al sereno (1916) y a otros bosquejos de menor importancia (Fischer, 1921: 14).

En este caso, los marcos de referencia son, indiscutiblemente, el discurso crítico sobre arte enfrentado a la tarea manual de pintar un rótulo. No obstante, resulta evidente la intención del traductor de intensificar el efecto humorístico haciendo que los dos marcos de referencia, el de la crítica de arte y el de los rótulos, resulten todavía más incompatibles al remitirlos al ámbito de lo reconocible por el lector de Buen Humor. De ahí que los rótulos apelen a la vida cotidiana de la España de 1921 -Llamad al sereno- e incluso a lugares específicos de Madrid, ya se trate de calles como la de la Visitación, ya de locales tan renombrados como el Gran Café de Pombo, elementos que no podían encontrarse en el original francés de los hermanos Fischer. De ahí también que en las alusiones al mundo del arte se hable del Salón de Otoño o del Museo del Prado, referencias que sustituyen sin duda a las del original - probablemente el Salón de París y el Museo del Louvre-, o se nombre a pintores y críticos famosos en el ámbito español como Manuel Benedito o José Blanco Coris.

Como traductor, López Rubio considera, sin duda, que la transposición es neceraria para que la incompatibilidad de los marcos de referencia quede bien clara para unos lectores que, no perteneciendo necesariamente a los estratos más cultos, debían reconocerla al primer golpe de vista, si no se quería que el efecto cómico se perdiese ante la extrañeza de tener que interpretar el papel que jugaban esos elementos desconocidos de la vida cotidiana o del ambiente artístico francés. Por esta razón, es habitual que en otras traducciones se realicen transposiciones semejantes, transformando los nombres de los protagonistas en su versión castellana, cambiando las monedas del original - francos, libras, dólares- en pesetas, o situando la acción en lugares reconocibles como la estación de Atocha. Como en el caso de «Un artista», lo esencial es que el lector se concentre en el recurso humorístico destinado a despertar la risa, evitándole cualquier otra cosa que pueda distraerle de ello.

Con todo, a partir del número 3, López Rubio cambia de táctica, acercándose a la primera de las posibilidades señaladas por Gaston Toury. Así, los textos de «Del buen humor ajeno» ya no se presentan como adaptaciones de ideas de otros autores, sino directamente como traducciones. Ello se debe, sin duda, a que el texto ofrecido en esta ocasión, el cuento 
«Los hermanos siameses» de Tristan Bernard ${ }^{6}$, no ofrecía ninguna necesidad de adaptación, aparte de la castellanización de los nombres de los personajes. Su humor se basa ya no en un planteamiento equívoco, sino en el absurdo: la historia que protagonizan los hermanos siameses del título ${ }^{7}$, dos jóvenes ingleses de caracteres muy diferentes -Eduardo es un serio erudito, mientras que Edmundo es un calavera juerguista-, recibe el mismo trato que cualquier drama familiar cuyos actores no estuviesen unidos por el cuerpo. Este tratamiento lleva al narrador a observaciones que resultan humorísticas por lo ociosas — «Eduardo había nacido en Manchester hace veinticinco años. Edmundo había nacido igualmente en Manchester hacia la misma época» (Bernard, 1921: 16) —, si acaso no es la misma condición de los gemelos siameses la que propicia una situación disparatada — «Y cuando Edmundo volvía borracho a casa, Eduardo no tenía más remedio que hacer eses con él, ruborizado, para no hacerse daño, por no quebrarse la espina dorsal» (Ibídem)-.

El relato alcanza su nivel más alto de inverosimilitud cuando Eduardo se casa con una joven que acabará engañándole con su propio hermano:

Al cabo de poco tiempo aconteció lo que llega a suceder cuando se aproxima un célibe a un matrimonio. Entre Cecilia y el pérfido Edmundo se establecieron unas relaciones culpables.

Durante seis meses Eduardo no se dio cuenta. Pero al fin acabó por enterarse. Encontró cartas en un cajón mal cerrado, y comprobó de una manera irrecusable que su mujer y su hermano le traicionaban diariamente. [...]

Hizo venir a Cecilia:

—Desde hoy — le dijo — no profanarás más el domicilio conyugal. ¡Vete!

-Bien - dijo ella.

—Bien — dijo Edmundo—. Pero yo la acompaño.

Y el pobre marido tuvo que seguirlos.

Edmundo instaló a Cecilia en una casita confortable en el campo. Y como todo suele arreglarse entre los xifópagos, nada turbó en lo sucesivo la felicidad de los tres (Bernard, 1921: 16).

Es evidente que el texto no presenta ningún problema en la traducción, puesto que la risa obedece a lo absurdo del planteamiento que, desde el primer momento, establece la incompatibilidad de los dos marcos de referencia en juego. El lector no necesita en esta

\footnotetext{
${ }^{6}$ Tristan Bernard (1866-1947) alcanzó gran fama como humorista escribiendo sobre todo para el teatro, aunque también triunfó en el periodismo y en la novela humorísticos. Fue conocido además por sus novelas policíacas y sus crucigramas. De raza judía, fue internado en 1943 junto con su mujer en el campo de concentración de Drancy, y sólo la intervención del dramaturgo Sacha Guitry y la actriz Arletty logró que le liberaran. No consiguió, sin embargo, evitar la muerte de su hijo François en Mauthausen.

${ }^{7}$ Es muy probable que este cuento influyera, de forma consciente o inconsciente, en la creación de la comedia de Enrique Jardiel Poncela Tú y yo somos tres (1945), si bien hay que consignar que el tratamiento que le dio Jardiel va mucho más allá de lo que plantea Bernard.
} 
ocasión que se le presente algo reconocible para poder contrastarlo con lo novedoso que va a plantear un equívoco. Aquí el mecanismo humorístico establece desde el principio unas reglas del juego que no se corresponden con las habituales, y a las que el lector debe someterse si quiere percibir la comicidad del texto ${ }^{8}$. De esta manera, es la traducción la que se pliega a las normas del texto fuente, ofreciendo así un relato mucho más original e interesante que «Un artista», en la medida que el cuento «Los hermanos siameses» prefigura el humor absurdo que será una de las señas de identidad de la nueva generación de humoristas.

La traducción del tercer texto, «Modos de hablar», de Pierre Veber ${ }^{9}$ - publicada en $^{2}$ el número 7 de Buen Humor-implica una síntesis de las dos opciones señaladas por Toury. $\mathrm{Al}$ igual que en el caso de «Un artista», el cuento surge de un planteamiento equívoco que, por lo demás, no deja de poner en evidencia, al igual que lo hacía «Los hermanos siameses», lo absurdo de ciertas convenciones sociales. El texto es tan breve que se puede citar en su totalidad:

Al pasar, les oí hablar. La señora Charoláis decía a la señora Fenouil:

- Sí; la he encerrado, no se me escapará la muy astuta.

—Es usted muy severa - le respondió la señora Fenouil.

-De ningún modo. Yo encuentro que es muy joven para hacer tonterías; casi todos los días, Tom, el de enfrente, desde que anda haciéndole la rosca, está en nuestra casa, buscando a la pequeña, naturalmente. Ayer me los encontré juntos: a él le señalé la puerta y a la pequeña le dije: «iComo yo tenga que castigarte, verás!» Ella, en vez de irse se quedó, buscando, sin duda, una caricia; pero yo no cedí, y le dije con gesto duro: «iNo, señorital». Créame usted, que si no se las trata así, puede ocurrirle algún día algo muy desagradable. Está muy mal educada, y quiere hacer siempre su gusto...; pero no puede ser. En esto soy inflexible, de hierro.

-Perdóneme — dije acercándome —. ¿Habla usted de su hija, señora Charoláis?

— iOh! No, señor. ¡Hablo de mi perrita!

Ocho días más tarde, al pasar, escuché de nuevo.

\footnotetext{
${ }^{8} \mathrm{El}$ humor absurdo del que es buena muestra este cuento no fue bien recibido por todo el público. Todavía en 1943 había lectores que no sólo se negaban a entrar en el juego, sino que además reaccionaban airadamente contra quienes se lo proponían, como hizo el anónimo lector de La Codorniz que envió a Miguel Mihura una carta haciendo alusión a un artículo de Emilio Rodríguez Lafuente donde se hablaba del nuevo género creado en las páginas de las revistas Buen Humor, Gutiérrez, La Ametralladora y La Codorniz, a lo que el lector respondía que «no puede ser rico en talento quien así escribe y se cree creador de algo que en lugar de avergonzarle le denomina un nuevo género. ¿Cuál? El género tonto, propio para estúpidos» (apud Llera, ed., 2007: 127).

${ }^{9}$ Pierre Veber (1869-1942) comenzó su carrera en periódicos y revistas como Gil Blas, y no tardó en escribir para el teatro, convirtiéndose en uno de los comediógrafos más prolíficos y populares de la época, sobre todo en el género del vodevil. Sus comedias fueron muy populares también en España. Se dedicó asimismo a la narrativa, escribiendo novelas y relatos que alcanzaron igualmente gran éxito. Sus descendientes se han dedicado también a la literatura, siendo el más destacado entre todos ellos su nieto Francis Veber, autor, entre otras obras, de La cena de los idiotas (1993).
} 
La señora Charoláis decía a la señora Fenouil:

- ¿No sabe usted? ¡Se me ha escapado la semana pasada! He preguntado en todas partes y nadie me ha sabido dar razón; algunos me han dicho que tengo yo la culpa de todo por no haberla atado corto... En fin, ya había perdido toda esperanza de volverla a ver, cuando ayer me la encontré delante de mi puerta..., con las orejas gachas. Entonces cogí el látigo y le grité: «iAh, cochina, trotacalles! ¡Te voy a matar!». ¡No sabe usted qué paliza le di!... ¡Ha sido una buena lección!... Charoláis?

- Perdón — dije acercándome —. ¿Habla usted de su perrita, no, señora

— ¡Ca! No, señor. ¡Hablo de mi hija!... (Veber, 1922).

Debe observarse que, por un lado, la incompatibilidad de los dos campos de referencia - la actitud y el discurso con que se refiere la señora Charoláis a su perra primero y a su hija después- no exige ninguna alteración del texto, que suscita la risa sin ningún problema. No obstante, dado que uno de los campos de referencia en juego atañe al discurso de la protagonista, el traductor se ve en la precisión de utilizar algunos modismos castellanos — «la rosca», «trotacalles», «Ca!»—que ayudan a mantener el equívoco. Sin embargo, se trata de pequeñas pinceladas que apenas afectan al resultado final: en esta ocasión, las modificaciones introducidas por el traductor se deben a su deseo de dar al texto un acabado formal adecuado, más que a su temor de que el lector no entre en las reglas del juego humorístico propuesto por el texto.

Si los comparamos con los cuentos humorísticos que producían los autores más acreditados de Buen Humor, los tres textos traducidos por José López Rubio son, con otros muchos que se irían publicando durante los diez años de existencia de la revista, una excelente demostración de hasta qué punto la nueva sensibilidad humorística a la que tendían, consciente o inconscientemente, los escritores más jóvenes de la redacción —encargados de la sección «Del buen humor ajeno»— buscaba algo diferente de los patrones del humor festivo que ya empezaba a percibirse como un recurso gastado. Se aplica en este caso, una vez más, el modelo de situación descrito por Itamar Even-Zohar:

La dinámica del polisistema crea puntos de inflexión, esto es, momentos históricos en los que los modelos establecidos ya no son aceptados por las generaciones más jóvenes. En tales momentos, incluso en las literaturas centrales, es posible que la literatura traducida asuma una posición central. Esto resulta aún más cierto cuando, en el punto de inflexión, no se acepta ninguno de los elementos del propio repertorio, por lo que se produce un «vacío» literario. Ante tal vacío, los modelos extranjeros se infiltran con facilidad y la literatura traducida puede adquirir una posición central. Por supuesto, en el caso de literaturas «débiles» o de literaturas que permanecen en un constante estado de empobrecimiento (al carecer de elementos existentes en literaturas vecinas o 
literaturas extranjeras accesibles), esta situación se acentúa todavía más (Even-

Zohar, 1990: 227).

Sería un error, con todo, hablar de influencias. Éstas, en realidad, proceden más del acervo nacional -las extravagantes farsas del tándem formado por Pedro Muñoz Seca y Enrique García Álvarez o las exageradas fantasías eróticas de Joaquín Belda, además de la arrebatadora fuerza de atracción que ejercitaba, desde una posición muy distinta, la obra de Ramón Gómez de la Serna- que de las escasas traducciones que se hacían del género cuentístico. No hay que olvidar que la popularidad de los Bernard, Veber, Courteline, etc., venía sobre todo del género teatral, cuyo humor estaba más dentro de los cauces de la comicidad festiva que del nuevo humorismo que podía encontrarse con cuentagotas en la prensa. Recordemos, por lo demás, que los textos más innovadores de la sección «Del buen humor ajeno» convivían con otros más tradicionales, inspirados incluso en tópicos como la tacañería de la raza judía —encontramos en más de una ocasión el «Mosaico de cuentos» atribuido a Jules Moy y Max Viterbo, desafortunada recopilación de chistes antisemitas centrados todos ellos en el tópico antedicho-.

Si hablamos del nuevo humor que surgió en los años veinte en España, en la generación nacida con el cambio de siglo, hay que tener en cuenta sobre todo las influencias nacionales sobredichas, junto con el propio temperamento de los aspirantes a suceder a la generación anterior, e incluso el propio espíritu de la época de las vanguardias, donde había una necesidad patente de acabar con lo viejo a base de propuestas innovadoras que rompiesen moldes. Sin embargo, tampoco hay que despreciar el papel que jugaron estas traducciones: los textos de Allais, Bernard, Courteline o Cami sirvieron de modelo de lo que se podía hacer en el terreno del humor, de hasta qué punto podía una voluntad iconoclasta alcanzar nuevas cotas en el humorismo. En este sentido, lo más adecuado sería hablar, más que de influencias, de confluencias. 


\section{BIBLIOGRAFÍA}

Bernard, Tristan (1921): «Los hermanos siameses», traducción al español de José López Rubio, Buen Humor, 3: 16.

Bourdieu, Pierre (1992): Las reglas del arte. Génesis y estructura del campo literario, traducción al español de Thomas Kauf, Barcelona, Anagrama. 4. ${ }^{a}$ ed., 2005.

Even-Zohar, Itamar (1990): «La posición de la literatura traducida en el polisistema literario», en Iglesias Santos (comp.), (1999): 223-231.

Fischer, Max y Alex (1921): «Un artista», traducción al español de José López Rubio, Buen Humor, 2: 14.

Iglesias Santos, Montserrat (comp.) (1999): Teoría de los polisistemas, traducción al español de Montserrat Iglesias Santos y Amelia Sanz Cabrerizo, Madrid, Arco.

Jardiel Poncela, Enrique (1922): «Un negocio productivo», Buen Humor, 32: 1-2.

Koestler, Arthur (1964): «El acto de la creación (Libro primero: el bufón)», traducción al español de Eva Aladro, Cuadernos de Comunicación e Información, 7 (2002): 189-220.

Llera, José Antonio (ed.) (2007): Epistolario selecto de Fuenterrabia, Valencina de la Concepción, Espuela de Plata.

López Ruiz, José María (1995): La vida alegre: historia de las revistas humorísticas, festivas y satíricas publicadas en la villa y corte de Madrid, Madrid, Compañía literaria.

López Ruiz, José María (2006): Un siglo de risas. Cien años de prensa de humor en España (19012000), Madrid, Libris.

Mihura, Miguel (1966): «Periodismo de humor», en Prosa y obra gráfica, edición de Arturo Ramoneda, Madrid, Cátedra, 2004: 1292-1308.

Ortega y Gasset, José (1925): La deshumanización del arte, en La deshumanización del arte y otros ensayos de estética. Madrid, Austral, 16. ${ }^{a}$ ed., 2008: 43-85.

Polo, Ernesto (1921): «La cena del poeta», Buen Humor, 4: 18-19.

Rodríguez de la Flor, José Luis, ed. (1990): El negociado de incobrables (La vanguardia del humor español en los años veinte). Madrid, De la Torre.

Rodríguez de la Flor, José Luis (1993): Prensa satírica en España (1832-1932). Madrid, De la Torre.

Torre, Guillermo de (1925): Literaturas europeas de vanguardia. Sevilla, Renacimiento, 2001.

Toury, Gaston (1995): «La naturaleza y el papel de las normas en la traducción», en Iglesias Santos (comp.), (1999): 233-255.

Veber, Pierre (1922): «Modos de hablar», Buen Humor, 7: 20. 


\section{SOBRE EL AUTOR}

\section{Juan Carlos Pueo}

Juan Carlos Pueo es profesor de Teoría de la Literatura y Literatura Comparada en la Universidad de Zaragoza desde 1995. Sus principales líneas de investigación se centran en las formas de la literatura cómica y en las relaciones entre la literatura y otras artes como la música o el cine. Ha publicado varios artículos sobre estos y algunos otros temas en diversas revistas y libros colectivos. Es autor de Ridens et Ridiculus. Vincenzo Maggi y la teoría humanista de la risa (Zaragoza, Trópica, 2001), Los reflejos en juego: una teoría de la parodia (Valencia, Tirant lo Blanch, 2002), Los usos de la palabra: el pensamiento literario de José María Valverde (Vigo, Academia del Hispanismo, 2011) y Como un motor de avión. Biografía literaria de Enrique Jardiel Poncela (Madrid, Verbum, 2016). Más información en https://linguistica.unizar.es/personal/ juan-carlos-pueo-dominguez.

Contact information: jcpueo@unizar.es 